\title{
Contextualism about Epistemic Reasons ${ }^{1}$
}

\author{
Daniel Fogal and Kurt Sylvan
}

\section{Introduction}

Ordinary talk is rife with claims about epistemic reasons. Consider, for example:

'There's no reason to think Yetis exist.'

'We have a reason to believe your account was accessed by a third party.'

'The dark clouds approaching are a reason to think it will rain.'

We will call sentences like these 'normative epistemic reasons ascriptions' ('ERAs' for short), since they are used to ascribe or deny reasons that normatively support beliefs. For simplicity, we will focus on unmodified ERAs like those above; talk of 'good'/'bad' reasons, 'strong'/'weak' reasons, etc., introduces further complexities. Normative reasons are standardly contrasted with explanatory and operative reasons. Perhaps the reason why Smith thinks he will never get a job is that he is depressedthis is an explanatory reason. But the fact that he is depressed needn't be his reason for so believing-i.e., it needn't be an operative reason for him. We aren't directly concerned with these kinds of reasons.

The line between different 'kinds' of reasons isn't perfectly sharp, however, and it's common to take all reasons-including normative reasons-to be essentially explanatory in nature. What distinguishes normative reasons from the rest is partly a matter of the kind of explanation involved-mere explanatory reasons are typically causal, while normative reasons are not-and partly a matter of their explanandumwhat normative reasons help explain are normative facts. Which normative facts? Three main candidates have been defended. According to the first, for $r$ to be a normative reason for an agent $S$ to $A$ (where $A$ is some action or attitude) is for $r$ to play a certain role in explaining why $S$ ought to $A$ (Broome 2004, 2013). According to the second, for $r$ to be a normative reason for $\mathrm{S}$ to $\mathrm{A}$ is for $r$ to play a certain role in explaining why it would be good for $S$ to A (Finlay 2014). And according to the third, for $r$ to be a normative reason for $\mathrm{S}$ to $\mathrm{A}$ is for $r$ to play a certain role in explaining why there is reason (mass noun) for $S$ to $A$ (Fogal 2016). Evidence for third option will be provided below.

The main goal in what follows is to survey some ways in which ERAs appear to be context-sensitive, and to outline a framework for thinking about the nature of this context-sensitivity that is intimately related to their explanatory function. These

\footnotetext{
${ }^{1}$ Forthcoming in The Routledge Handbook to Epistemic Contextualism, ed. Jonathan Jenkins Ichikawa. Thanks to Jonathan Shaheen and Justin Snedegar for helpful comments.
} 
are the main tasks of $\$ 2-3$. We won't pretend to have covered all forms of apparent context-sensitivity, nor to have settled the question of their nature and source. Surprisingly little work has been done on ERAs, despite the fact that ERAs strike us as more promising candidates for contextualist treatment than knowledge ascriptions. Our primary aim is thus to bring increased attention to an underexplored issue.

\section{Data}

In this section, we highlight several ways in which ERAs appear to be context-sensitive. To maintain neutrality between pragmatic and semantic explanations of such appearances, the initial judgments (or 'data') we consider are not presented as directly concerning the truth conditions of ERAs. Instead, they concern their acceptability conditions-roughly, the circumstances in which it is acceptable for a competent speaker who knows all the relevant non-semantic facts to use the ERAs.

\subsection{Sensitivity to Relevant Alternatives}

Some apparent contextual variability in the acceptability of ERAs is triggered by changes in which alternative hypotheses are relevant in the conversational context (Dretske 1970, Stine 1976). Consider a relatively ordinary context in which we are asked whether some animal in a picture is a zebra. In such a context, it would be acceptable to say:

(1) The fact that it is striped is a reason to believe it is a zebra.

But now consider a context in which the possibility that the animal is a cleverly disguised mule-one with painted stripes, etc.-is being seriously entertained. In that context, (1) would be significantly less acceptable-so much so that its negation (2) seems OK:

(2) The fact that it is striped is not a reason to believe it is a zebra.

The acceptability of ERAs thus appears to be sensitive to which alternative hypotheses are contextually relevant. In particular, such patterns suggest that a claim of the form ' $p$ is a reason to believe $q$ ' will be acceptable in a context $c$ only when it is true that

(Alt) $p$ is a reason to believe $q$ rather than $r_{i}$, where $r_{i}$ are the relevant alternative hypotheses to $q$ in $c$. 
Epistemic contextualism in its earliest form was closely related to such a view. ${ }^{2}$ While the debate between Stine and Dretske focused on 'knows', both made analogous claims about 'reason(s)'. More recent elaborations of this idea in the literature on ERAs tend to fall under the heading of 'contrastivism', with contrastivists arguing that the reason(s)-relation has an extra argument place for relevant alternatives, or 'contrasts', an argument place filled by context but phonologically null (SinnottArmstrong 2008; Snedegar 2013a, 2015).

The status of this view depends in part on what relevance amounts to, and how it is determined. If the relevance of an alternative is determined solely by facts about the subject of the ERA — say, by facts about their mental states, evidence, or situation more generally-then no support accrues for contextualism, since the relevant alternatives wouldn't vary across conversational contexts. If, on the other hand, the relevance of an alternative is determined partly by facts about the speaker, then (some form of) contextualism would follow, since the relevant alternatives could vary with the speaker across contexts.

There are other possible explanations of the data involving (1). In particular, one might think that the relevant version of (Alt), along with various other natural strengthenings of (1)-e.g., the claim that the stripes are a strong or weighty reason to believe that the animal is a zebra-are merely pragmatically conveyed (Schroeder 2007). On this view, even if an utterance of (1) might pragmatically convey something false in a context in which the possibility of the animal being a cleverly disguised mule is entertained, the proposition semantically expressed by (1) is true: the fact that the animal is striped is a reason to believe that it is a zebra, even though it may not be a decisive or even a particularly good reason, and even though it may not be a reason to believe that it is a zebra rather than a cleverly disguised mule. As evidence of their 'merely' pragmatic status, one might point out that many such strengthenings appear to be cancellable. For example, in the original context one might utter (1) and then continue: 'Of course, it's hardly decisive-perhaps it's just a cleverly disguised mule.' Similarly, in the second context one might utter (1) and then continue: 'I realize, though, that the stripes are just as much a reason to believe it is a cleverly disguised mule-I don't mean to rule that possibility out.'

Even if we can explain why, despite being true, (1) is unacceptable in a context where the cleverly disguised mule possibility is entertained, it remains to be explained why (2) is acceptable despite being false (cf. Snedegar 2013b). The unacceptability of (1) despite its truth was traced to the unacceptability of what was pragmatically conveyed. Analogously, we might try to explain the acceptability of (2) in such a context by appealing to the acceptability of what it would pragmatically conveye.g. the fact that it is striped is not a sufficiently good reason to believe that it is a zebra, or is not a reason to believe that it is a zebra rather than a cleverly disguised mule.

\footnotetext{
${ }^{2}$ Dretske (1970) discusses pro tanto reasons talk; Dretske (1971) discusses overall reasons talk. Dretske (1972) contains a seminal discussion of contrastive statements in general, including ones concerning explanatory reasons.
} 
Alternatively, one might think (2) is acceptable when seemingly false only if 'not' is interpreted metalinguistically, in which case (2) wouldn't actually be false (cf. Horn 1989). In particular, a metalinguistic use of 'not' might have the effect of saying that the fact that it is striped shouldn't count or be considered as a reason to believe that it is a zebra in the relevant context-perhaps, again, because it's not sufficiently good, or doesn't bear on the question of whether it's a zebra or instead a cleverly disguised mule.

Assuming utterances of (1) and/or (2) would normally pragmatically convey something of the form of (Alt), there remains the question of how that happensi.e., what pragmatic 'mechanism' is underwriting the process. Here a variety of stories might be told. For example, one might think that the relevant instance of (Alt) has the status of a conversational implicature. For in normal contexts it will fairly clear which alternatives are relevant, with one of the conversational goals being to decide between them. If so, then it would be pointless to utter (1) unless one also wanted to communicate something (Alt)-like (cf. Grice's Maxim of Quantity), and although one could make an explicitly contrastive claim instead of uttering (1), doing so would be needlessly verbose (cf. Grice's Maxim of Manner). Another possibility would be to claim that (1) can be used to directly but implicitly communicate what utterances taking the form of (Alt) explicitly communicate, as the result of a process of so-called 'pragmatic enrichment' (cf. Sperber and Wilson 1986/1996, Bach 1994, Recanti 2004). For more on the similarities and differences between conversational implicature and various forms of pragmatic enrichment, see Chapters 16 and 37.

Alternative semantics provides another way to explain how (1) might be used to communicate something (Alt)-like. According to alternative semantics, the general function of focus is to evoke alternatives, and an additional semantic value for each sentence is posited to accommodate this fact (Rooth 1992). Sentences therefore come with both ordinary semantic values and focus semantic values, with the latter consisting of a set of alternatives. As Rooth (1996) notes,

The basic idea [can] be illustrated with the question-answer paradigm. The question [does Ede want tea or coffee?] determines the basic answers "Ede wants tea" and "Ede wants coffee". Similarly, focus in the answer [Ede wants [coffee $]_{\mathrm{F}}$ ] indicates that propositions obtained by making substitutions in the position of the focused phrase-propositions of the form "Ede wants $y$ "-are alternatives to the actual answer. Congruence is simply a matter of the question and answer characterizing the answer set consistently.

On this view, a sentence like (1) will thus have a focus semantic value in addition to its ordinary semantic value, with the former depending on which phrase is focused. The sentence [The fact that it is striped is a reason to believe it is a $[z e b r a]_{\mathrm{F}}$, for example, will have as its focus semantic value the set of propositions of the form "The fact that it is striped is a reason to believe it is a $X$ ", with possible values of $X$ being contextually constrained. 


\subsection{Sensitivity to Questions}

A related kind of apparent context-sensitivity is connected to the explanatory nature of reasons ascriptions. As many have observed, it seems a truism that reasons-ascriptions-and explanations more generally-are answers to 'why'-questions (cf. Hempel 1965, Bromberger 1966, van Fraassen 1980, Jenkins 2008). ${ }^{3}$ The questions ERAs answer concern why certain normative facts obtain. On this picture, one would expect the acceptability of ERAs to be sensitive to the question(s) under discussion, which may vary contextually.

To illustrate, consider a general theory (e.g. nominalism about properties) with its specific variants (e.g., trope theory and predicate nominalism), and to which there is a general alternative (e.g., realism about universals). Suppose the following questions interest us:

(Q1) Why believe trope theory rather than realism about universals?

(Q2) Why believe trope theory rather than predicate nominalism?

If we focus on (Q1), the following claim seems acceptable:

(3) The fact that trope theory provides a parsimonious ontology is a reason to believe it.

But if we instead focus on (Q2), (3) seems significantly less acceptable-after all, trope theory and predicate nominalism are similarly parsimonious. It's a further question whether (3) is false in such a context. We thus face a similar range of choices as above in offering a semantic and/or pragmatic explanation of the context-sensitivity.

It's worth noting that (Q1) and (Q2) are normative or deliberative questions. They concern why we should believe something, and the facts appropriately cited as reasons in response to them help settle the relevant question. Often, however, the questions that interest us aren't normative. How then should we interpret ERAs in contexts in which normative questions aren't under discussion, even implicitly? ${ }^{4}$ Although space precludes detailed discussion, we doubt there are such contexts. Suppose, for example, that I ask you whether our neighbor Jim is home. You look across the street and see his car in the driveway. You then say, 'Well, I'm not sure, but the fact that his car is in the driveway is a reason to think he's home'. This response fails to answer the original question concerning Jim's location, but it's not completely irrelevant. Instead, you opt out of answering the original question by expressing uncertainty concerning the correct answer and seek to provide the next best

\footnotetext{
${ }^{3}$ These answers may only be partial, rather than full, and merely possible, rather than actual.

${ }^{4}$ Thanks to Justin Snedegar for raising this issue.
} 
thing-namely, information relevant to answering the question. ${ }^{5}$ Here the question is theoretical, and information relevant to it will typically take the form of evidence concerning the truth or falsity of possible answers. In other words, it will take the form of reasons to believe one answer rather another. Given your inability to answer the original, non-normative question-namely, whether Jim is home-the natural thing to do is to pivot and provide an answer to a related, normative one-namely, whether there is any reason to think Jim is home (and if so, why). We think something like this is true in general when we use ERAs in answering seemingly nonnormative questions.

Assuming the acceptability of ERAs is indeed sensitive to the question(s) under discussion, there's a further issue concerning whether it's distinct from sensitivity to relevant alternatives. It's standard in semantics, for example, to treat questions as presenting sets of alternatives, or possible answers. If so, then the question-sensitivity of ERAs would amount to sensitivity to relevant alternatives. This form of relevant alternatives contextualism would have the advantage of being able to draw from, and build on, the active and ongoing research program in formal semantics and pragmatics concerning the question under discussion, along with many other ways in which information in a discourse can be structured (see, e.g., Roberts 2012a,b).

\subsection{Sensitivity to Information}

Changes in which body of information is relevant provide another example of how the acceptability of ERAs appears to vary depending on the context of utterance (cf. Cohen 1986). Indeed, there is growing recognition that the familiar (and not necessarily binary) distinction between more 'objective' and more 'subjective' readings of claims concerning normative reasons for action extends to ERAs (cf. Schroeder 2008, 2011, 2015). ${ }^{6}$

Suppose Jones is a detective at the scene of a crime who stumbles across evidence that implicates Smith, a notorious criminal, though Jones lacks information needed to connect the dots. And imagine Jane, another detective, has the same in-

\footnotetext{
${ }^{5}$ Indeed, as Jonathan Shaheen (p.c.) notes, the hesitation marker 'well' is often used to signal that you are doing something other than providing a complete answer to a question.

${ }^{6}$ One common way of drawing the distinction is in terms of the reasons there are for some agent $S$ to $A$ (so-called "objective reasons") and the reasons $S$ has to $A$ (so-called "subjective reasons"). Although we grant that there is an important distinction in the vicinity, there are many complications concerning how such a distinction is to be understood, and how (if at all) it manifests itself in ordinary thought and talk. It seems doubtful the distinction is encoded in natural language-talk of reasons 'there are' and reasons 'had' is (for the most part) interchangeable. See Sæbø's (2009) for a semantic analysis of 'have'-sentences that predicts and explains their interchangeability with 'there is'-sentences. For a possible complication concerning this equivalence, see Broome (2013: 65).
} 
formation as Jones. Jones wonders aloud whether Smith is culprit. Turning to Jones, Jane says:

(4) Perhaps-but as of now we don't have a single reason to believe that he did it.

Smith, meanwhile, overhears Jane's claim—he has a habit of lurking around crime scenes in disguise-and mutters to himself:

(5) Ha! They do have a reason to believe I did it, though they'll never appreciate it.

Assuming both (4) and (5) are acceptable, one might take this as evidence that ERAs are always relativized-if only implicitly-to bodies of information, and that which body of information is relevant may vary between contexts, and perhaps even within a context. On this view, (4) might express the proposition that relative to the information actually possessed by the detectives, the detectives lack a reason to believe Smith committed the crime. (5), by contrast, might express the proposition that relative to some enhanced body of information, the detectives have a reason to believe that Smith committed the crime. This yields a view on which ERAs are information-sensitive in much the way modals like 'ought' are thought to be. ${ }^{7}$

Henning (2014) pursues the apparent analogy between 'reason(s)' and 'ought', arguing that claims of the form ' $r$ is a reason for $S$ to believe that $p$ ' can be used to communicate an indefinite number of propositions of the form

$\left({ }^{*}\right)$ Relative to body of information $i, r$ is a reason for $S$ to believe that $p$.

According to Henning, any body of information can, in principle, determine the value of the parameter $i$. Candidates include the following:

i. The information possessed by some relevant individual.

ii. The information possessed by some relevant group or community.

iii. The information easily-accessible-in-principle by some relevant individual or group.

iv. All the information in the world.

${ }^{7}$ Cf., e.g., Kolodny and MacFarlane (2010) and Dowell (2011). Another parallel with deontic modals arises if we consider the much-discussed mineshafts case, where a miner lacking full information seemingly acceptably utters 'I ought to block neither shaft', and someone with more information says 'No, you ought to block shaft A'. Many philosophers assume the two disagree. A parallel claim might be made about Jane and Smith when they utter (4) and (5) -a parallel that would be strengthened if Smith's remark were prefaced by 'That's false...' This might suggest that ERAs are sensitive to the context of assessment (cf. MacFarlane 2014). The data surrounding cases of apparent disagreement is more complicated than commonly thought, however-see Chapter 20. 
Those wishing to defend invariantism about ERAs in the face of data concerning information-sensitivity face a challenge like those wishing to defend invariantism about modals. ${ }^{8}$ We cannot discuss those challenges in depth, but we suspect it will be an uphill battle.

\subsection{Sensitivity to Standards and Thresholds}

A consideration $r$ can be a reason to believe $p$ even if $r$ doesn't entail $p$. Indeed, it often seems sufficient that $r$ raises $p$ 's probability to some degree. To what degree, however, must $r$ raise the probability of $p$ in order to count as a reason for believing $p$ ? One might think there's no fixed answer to this question, and that ERAs can be true or false in different contexts depending on the stringency of the relevant threshold or standard. Consider, for example, a claim like the following:

(6) Lena has a reason to think John was at work today-she saw his coat and hat hanging outside his office door.

In a causal discussion at a tavern, (6) might be perfectly acceptable. But when being interviewed by a detective trying to determine whether John was at the scene of the crime, it might not be. ${ }^{9}$ Such a contrast, insofar as it exists, could be taken as a reflection of different standards being operative in the two contexts. In the first context, for example, in order for $r$ to count as a reason to believe $p$, perhaps $r$ just needs to increase the probability of $p$ to some degree or other, whereas in the second context perhaps $r$ needs to substantially increase the probability of $p$. Alternatively, such a contrast may be susceptible to a pragmatic explanation. It's plausible, for example, that (6) would normally be used to communicate something more than the mere fact that Lena has a reason to believe John was at work, and what that reason is. In particular, it would be used to communicate something (via either conversational implicature or pragmatic enrichment) about the strength of Lena's reason-namely, that is was a relatively strong reason. And it is unsurprising that what counts as a 'strong' reason can vary between contexts depending on the operative standards (and, at least indirectly, stakes), since gradable adjectives like 'strong' are plausibly context-sensitive in just this way (cf. Stanley 2005; Kennedy 2007). So even if talk of reason(s) per se isn't sensitive to standards or thresholds, talk of strong/weak/good/ bad reasons will be.

Standards-sensitivity figured prominently in early discussions of contextualism. Stine (1976)'s view, for example, was doubly contextualist. She was a relevant alternatives contextualist about knowledge ascriptions, but her preferred account of relevance was understood in terms of epistemic reason(s) - according to her 'an alternative is relevant only if there is some reason to think that it is true' (252). But Stine

\footnotetext{
${ }^{8}$ For a recent overview, see Bronfman and Dowell (forthcoming).

${ }^{9}$ Cf. DeRose (2009: 4-5).
} 
also embraced a standards-relative contextualism about ERAs, arguing that the context-sensitivity of knowledge ascriptions is

directly mirrored by the fact that we have different standards for judging that there is some reason to think an alternative is true, i.e., relevant. We can point out that some philosophers are very perverse in their standards (by some extreme standard, there is some reason to think there is an evil genius, after all)... [and] in fact they have played on an essential feature of the concept. (254)

What might such an 'extreme' standard-one relative to which there is some reason to think there is an evil genius-look like? There are various possibilities. For example, one might operate with a standard according to which $r$ is a reason to believe $p$ if (but not necessarily only if) $r$ 's being true would explain $p$. Assuming the existence of the relevant evil genius would explain the fact that I have the perceptual experiences that I do (among other things), it might then be acceptable to utter the following:

(7) There is a reason to think there is an evil genius. ${ }^{10}$

One might then think that although the proposition expressed by (7) is true in contexts like the one just envisaged, in normal contexts-i.e. when a different standard is operative-it is false. Alternatively, one might think the proposition expressed by (7) is true in normal contexts as well, with its unacceptability being explained by familiar pragmatic means.

\subsection{Reasons and Background Conditions}

Two further kinds of apparent context-sensitivity in ERAs parallel kinds of contextsensitivity in causal talk. Firstly, as with causal talk, what is most naturally cited as a reason and what is treated as a mere 'background' condition seems contextually variable. Consider a match being struck in an oxygenated environment and lighting. Although some might claim that only the striking of the match is a (or 'the') cause of the fire-with the oxygen merely being a background condition-there are contexts in which the underlying metaphysics remains the same and yet what we're inclined to count as a (or the) cause changes. Imagine that the match is being repeatedly struck in a vacuum when oxygen suddenly rushes in, or that we are aliens from an oxygen-deficient planet observing the striking from afar (cf. Putnam 1982). Here it would be natural for the presence of oxygen to be cited as a cause, and not merely a background condition.

It's plausible to view this contextual variability as a form of information-sensitivity, where what varies between contexts is not which body of information is rele-

\footnotetext{
${ }^{10}$ It may help to imagine a continuation of (7) that explicitly cancels any implication of strength-e.g. '...though it's not a very good reason'. (Cf. Schroeder 2007)
} 
vant per se but instead which parts of that information are taken for granted or held fixed for the purposes of communication, and which parts are highlighted or viewed as especially noteworthy. This isn't to deny that there are meaningful distinctions to be drawn between different metaphysical roles that certain facts or events may play in explaining other facts or events. But it is to deny that ordinary language reliably tracks such distinctions. Differences in communicative relevance needn't reflect differences in metaphysical significance.

The same dialectical situation arises with respect to ERAs. Imagine a world, for example, in which only smokers with gene $\mathrm{X}$ get cancer, with an incident rate of $40 \%$. Imagine further that the world is divided into two isolated populations, P1 and $\mathrm{P} 2$. In $\mathrm{P} 1$, it is common knowledge that most people have gene $\mathrm{X}$ but few people smoke. In P2, it is common knowledge that few people have gene $\mathrm{X}$ but most people smoke. Now, imagine the following possible answers to the question of what reasons there are to think that a given person will get cancer:

(8) The fact that a person smokes is a reason to think she will get cancer.

(9) The fact that a person has gene $X$ is a reason to think she will get cancer.

The acceptability of these claims will likely vary depending on the population. In particular, (8) will be significantly more acceptable than (9) in P1 while in P2 the reverse pattern will hold. As before, it's plausible to view this as a form of information-sensitivity, since the only relevant differences between the populations concern the information at their disposal. But just because it's more natural to cite one fact rather than the other in a particular context needn't reflect a difference in epistemological significance. Differences in communicative relevance needn't reflect differences in epistemological significance any more than they reflect differences in metaphysical significance. ${ }^{11}$

\subsection{Reasons as Representatives}

There is a second parallel between causal claims and ERAs that one of us has explored elsewhere (Fogal 2016). In response to the fact that what we're inclined to cite as 'the cause' of an event varies greatly from context to context, Lewis (1973) famously remarked:

I have nothing to say about these principles of invidious discrimination. I am concerned with the prior question of what it is to be one of the causes (unselectively

\footnotetext{
${ }^{11}$ Jonathan Shaheen (p.c.) notes that this can be reinforced by finding a context involving members of P1 in which something like (9) is acceptable. Consider, for example, the following exchange:

A: I know Jane smokes, unlike everybody else around here, but I really didn't think she'd get cancer.

$\mathrm{B}$ : Me neither. But as you know Jane has gene $\mathrm{X}$, and that is a reason to have thought she would get cancer.
} 
speaking). My analysis is meant to capture a broad and nondiscriminatory concept of causation. (559)

However, as Swanson (2010, 2012) argues, a similarly 'invidious' contextual variability infects our judgments involving 'a cause' or 'one of the causes', and failure to appreciate it has led subsequent theorizing astray. According to Swanson, the events we cite as causes function as "representatives" of the causal chains leading them to the effect; as a result, whether a given causal claim is acceptable partly depends on what else has been cited as a cause (and hence used as a representative) in the context.

The acceptability of ERAs appears to exhibit the very same sort of variability. To illustrate, suppose Candice looks through a window and sees a room filled with smoke. In explaining what grounds she has to believe there's a fire you might say either of the following:

(10) That fact that she sees smoke is a reason for Candice to believe there's a fire.

(11) The fact that smoke is a sign of fire is a reason for Candice to believe there's a fire.

But it would be unacceptable to say any of

(12) \#The fact that she sees smoke is a reason for Candice to believe there's a fire, and so is the fact that smoke is a sign of fire.

(13) \#The fact that she sees smoke and the fact that smoke is a sign of fire are both reasons for Candice to believe there's a fire.

(14) \#Candice sees smoke and knows that smoke is a sign of fire, so she has two reasons to believe there's a fire.

ERAs like (12)-(14) seem guilty of double-counting. What this shows-assuming the above pattern of judgments generalizes-is that the facts we usually cite as reasons are not themselves sources of epistemic support. Instead, they function communicatively as representatives of a larger cluster of facts that together (and only together) provide such support. What can be appropriately cited as a reason in a given context will thus partly depend on what else we've cited as a reason, since citing one fact as a reason-and hence as a representative of a given cluster-robs other facts belonging to that cluster of the representative role they might have played.

This reinforces the point that we should be wary of assigning undue significance to the facts we cite as reasons in using ERAs. It's doubtful that the sight of smoke is epistemically relevant in a way that the known connection between smoke and fire is not, and arguably it's only in virtue of both taken together that Candice has reason to believe there's a fire. The facts we ordinarily cite as reasons don't themselves play a privileged epistemic role.

It's debatable whether the representative-like role facts cited as reasons is merely pragmatic or instead partly semantic. One might think (12)-(14) are defective solely in virtue of being pointless, irrelevant, misleading in virtue of generating a 
false implicature, etc., despite being true. Note, however, that there don't appear to be continuations of (12)-(14) in the relevant context that cancel or eliminate their infelicity, contrary to what one might expect if their defectiveness was purely pragmatic. Instead, their defectiveness seems more akin to that involved in certain cases of presupposition failure, which is often treated as a partly semantic phenomenon. ${ }^{12}$

\section{Reasons and Explanation}

The analogies between reasons talk and causal talk run deep. The similarities become less surprising once it's realized that claims about reasons and about causes are both explanatory claims, and essentially so. That is, they are claims the point of which is to explain why things (facts, states, events, whatever) are the way they are, rather than merely report how things are. This point of commonality is controversial, but not without precedent. Here is Strevens (2007), for example, on the explanatory nature of causal claims:

...the role of causal claims in science and everyday life is not to express basic metaphysical facts about causal connections, but rather to extract from the basic causal facts an understanding of how causal connections work together to bring about certain states of affairs. The question of the meaning of causal claims turns out to be less a question about metaphysics, then, and more a question about understanding or explanation... [it has] been an error-a major and pervasive error-for causal metaphysicians to have focused so great a part of their energies on causal claims. (107)

We think an analogous point holds with respect to ERAs, since reasons help to explain normative facts. Which normative facts do reasons help explain? In the introduction we noted that there have been three main proposals, and that our sympathies are with the third-that for $r$ to be a reason (count noun) for $S$ to $A$ is for $r$ to help explain why there is reason (mass noun) for $S$ to $A$. To bring out the essentially explanatory nature of ERAs, it will help to say more.

Intuitively, count nouns denote (classes of) 'things' that are countable, and hence can occur with cardinal numerals ('one', 'two', 'three'...) and take plural form $(-s)$, while mass nouns denote 'stuff' that's not countable, and hence do not occur with cardinal numerals and are generally singular or unmarked. There's a lot to be said about the mass/count distinction, but what matters most is that 'reason' in its normative sense is regularly used both ways. Superlative and comparative claims concerning what one has most or more reason to do, for example, are commonplace and obviously not equivalent to the corresponding superlative and comparative claims concerning what one has most or more reasons to do. The same goes for quantitative judgments concerning how much reason there is, whether there is enough reason, and so on. 'Reason' is hardly unique in being used as both a mass noun and a

\footnotetext{
${ }^{12}$ For an introduction to presupposition (and its failure), see Beaver and Geurts (2014).
} 
count noun; indeed, it is common for nouns in languages with mass-count syntax to be used both ways, and there are well-established patterns underlying such alternations.

This raises a question about the relationship between mass and count uses of 'reason'. Although space precludes detailed discussion, the relationship is plausibly the same as that which holds between mass and count uses of 'pleasure', 'sorrow', and 'light' (see Fogal 2016). Just as pleasures are sources of pleasure, sorrows are sources of sorrow, and lights are sources of light, so normative reasons are "sources" (or grounds) of normative reason-i.e., they are sources of normative support. Importantly, however, there's an explanatory asymmetry involved: in each case the 'things' denoted by the count noun (pleasures, lights, reasons) are functionally defined in terms of the role they play in explaining the "stuff" denoted by the mass noun (pleasure, light, reason), rather than vice versa. So just as it would be a mistake to analyze pleasure in terms of pleasures, or light in terms of lights, so it would be a mistake to analyze reason in terms of reasons. Instead, we should analyze normative reasons in terms of reason (i.e. normative support): reasons to $\varphi$ are things which play a certain role in explaining why there is reason to $\varphi$. This view readily explains why (3), reprinted from above, is intuitively equivalent to (3')-(3'):

(3) The dark clouds approaching are a reason to think it will rain.

(3') The dark clouds approaching give us reason to think it will rain.

(3") There are dark clouds approaching, and that's why there is reason to believe it'll rain.

Notice that the fact cited as a reason in (3) is cited as that which explains why there is (mass-y) reason in (3')-(3"). It's hence plausible to view claims about normative reasons as inherently explanatory. Given that ordinary explanatory claims are widely agreed to be context-sensitive, it's only to be expected that ERAs-and reasons ascriptions in general-are context-sensitive, and in much the same way. ${ }^{13}$ We can profitably understand the question-sensitivity and information-sensitivity of ERAs as symptoms of this fact, since explanatory claims are sensitive to both.

None of this directly settles the matter concerning the precise nature of the context sensitivity at issue with ERAs, or how best to model it as part of a serious semantic theory. These remain open questions. Schaffer (2012) makes a similar point concerning the context-sensitivity of causal claims, concluding his survey by arguing not only that "we do not yet have a clear understanding of context sensitivity as it arises for causal claims", but also that this is "everyone's problem" (55). We think the same is true of the context-sensitivity of ERAs, and reasons claims more generally.

The good news is that there is a clear direction for research, at least on the assumption that the context-sensitivity of ERAs is an instance of the context-sensitivity of explanatory claims more generally: to better understand the semantics and pragmatics of the former, we need to better understand the semantics and pragmatics of

${ }^{13}$ This is after possible ambiguity is controlled for-see, e.g. Shaheen (forthcoming). 
the latter. Despite the controversies that have plagued debates about explanation and our explanatory practice over the past few decades, genuine progress has been made, and we should expect many of the lessons learned in the debates over causal and scientific explanation to carry over to normative explanation, and locutions used to provide such explanations. ${ }^{14}$ However, philosophers interested in explanation rarely try to provide semantically sophisticated analyses of explanatory terms themselves, or integrate their accounts into a larger semantic framework. ${ }^{15}$ This is perhaps unsurprising - the information-sensitivity of explanatory claims is deep and pervasive, and so it is only to be expected that natural language evolved in such a way that sentences containing explanatory locutions are always evaluated relative to both a question and an informational background, without there being any simple rules governing such relationships. This is in sharp contrast to the rules governing indexicals like 'I'. There nonetheless remains much interesting and important work to do by philosophers and linguists alike in better understanding our explanatory practice as well as the variety of different locutions we use in the service of providing explanations, such as ERAs.

\section{Conclusion}

While hard work remains, there is much to be said in favor of contextualism about ERAs. This matters. Given the variety of challenges confronting contextualism about knowledge ascriptions (cf. Stanley 2005; see also Chapters 25, 27, and 25), one might be forgiven for thinking that contextualism in epistemology more generally is implausible. But there is a lot more to epistemic language than 'knows', and careful examination of the linguistic evidence in other cases-such as ERAs-encourages revival of the contextualist project. There are many important disanalogies between 'reason(s)' and 'know(s)'. This includes the fact that unlike 'knows', 'reason' is gradable when used as a mass noun (there can be more or less reason to $\varphi$ ) and is conceptually linked with a scale of normative strength or weight even when used a count noun (some reasons are better/worse/stronger/weaker than others). There are also several avenues of possible support for contextualism about ERAs that lack obvious analogues in the case of 'knows', as the data in $\$ 2.3$ and $\$ 2.5-2.6$ illustrate. So pessimism about contextualism about knowledge ascriptions does not warrant pessimism about contextualism about other epistemic terms.

\footnotetext{
${ }^{14}$ This is especially true if Skow (2016) is right that theories of explanation are best understood as theories of reasons why, given that normative reasons are just a special kind of reason why.

${ }^{15}$ There are some exceptions—see, for example, Nickel (2010).
} 


\section{References}

Bach, K. 1994. “Conversational Impliciture.” Mind \& Language 9(2): 124-162.

Beaver, D. and Geurts, B. 2014. "Presupposition", The Stanford Encyclopedia of Philosophy (Winter 2014 Edition), Edward N. Zalta (ed.), URL = <http://plato.stanford.edu/archives/win2014/entries/presupposition/>.

Bromberger, S. 1966. "Why-Questions" in Colodny, R. (ed.) Essays in Contemporary Science and Philosophy. Pittsburgh: University of Pittsburgh Press.

Bronfman, A. and Dowell, J. Forthcoming. "The Language of Reasons and Ought" in Star, D. (ed.) The Oxford Handbook of Reasons and Normativity. Oxford: Oxford University Press.

Broome, J. 2004. 'Reasons' in Wallace, R. J., Smith, M, Scheffler, S. and Pettit, P. (eds.) Reason and Value: Themes from the Moral Philosophy of Joseph Raz. Oxford: Oxford University Press.

—_ 2013. Rationality through Reasoning. Wiley Blackwell.

Cohen, S. 1986. "Knowledge and Context." Journal of Philosophy 83: 574-583.

DeRose, K. 2009. The Case for Contextualism. Oxford: Oxford University Press.

Dowell, J. L. 2011. "A Flexible Contextualist Account of Epistemic Modals." Philosophers' Imprint 11(14): 1-25.

Dretske, F. 1970. "Epistemic Operators." Journal of Philosophy 67: 1007-1023.

__ 1971. "Conclusive Reasons." Australasian Journal of Philosophy 49: 1-22. 1972. "Contrastive Statements." The Philosophical Review 81: 411-437.

Finlay, S. 2014. A Confusion of Tongues: A Theory of Normative Language. Oxford: Oxford University Press.

Fogal, D. 2016. "Reasons, Reason, and Context" in Lord, E. and Maguire, B. (eds.) Weighing Reasons. Oxford: Oxford University Press.

Grice, H. P. 1989. Studies in the Way of Words. Cambridge MA: Harvard University Press.

Hempel, C. 1965. "Aspects of Scientific Explanation" in his Aspects of Scientific Explanation and Other Essays in the Philosophy of Science. London: CollierMacmillan.

Henning, T. 2014. "Normative Reasons Contextualism." Philosophy and Phenomenological Research 88: 593-624.

Horn, L. 1989. A Natural History of Negation. Chicago: University of Chicago Press.

Jenkins, C.S. 2008. "Romeo, René, and the Reasons Why: What Explanation Is." Proceedings of the Proceedings of the Aristotelian Society 108: 61-84.

Kennedy, C. 2007. "Vagueness and grammar: the semantics of relative and absolute gradable adjectives." Linguistics and Philosophy 30: 1-45.

Kolodny, N. and MacFarlane, J. 2010. "Ifs and Oughts." Journal of Philosophy 107(3): 115-143.

Leslie, S. 2007. "Moderately Sensitive Semantics" in Preyer, G. (ed.) Context Sensitivity and Semantic Minimalism. Oxford: Oxford University Press.

Lewis, D. K. 1973. "Causation." Journal of Philosophy 70: 556-567.

MacFarlane, J. 2014. Assessment Sensitivity Relative Truth and its Applications. Oxford: Oxford University Press. 
Nickel, B. 2010. "How General Do Theories of Explanation Need to Be?" Nous 44(2): 305-328.

Putnam, H. 1982. "Why There Isn't a Ready-Made World." Synthese 51: 141-167.

Recanati, F. 2004. Literal Meaning. Cambridge: Cambridge University Press.

Rooth, M. 1992. "A Theory of Focus Interpretation." Natural Language Semantics 1: $75-116$.

__ 1996. "Focus" in Lappin, S. (ed.) The Handbook of Contemporary Semantic Theory. Oxford: Blackwell.

Roberts, C. 2012a. "Information Structure in Discourse: Towards and Integrated Formal Theory of Pragmatics." Semantics \& Pragmatics 5(6): 1-69.

__ 2012b. "Information Structure: Afterword." Semantics and Pragmatics 5(7):119.

Sæbø, K. J. 2009. "Possession and Pertinence: The Meaning of 'Have'." Natural Language Semantics 17(4): 360-397.

Schaffer, J. 2012. "Causal Contextualism" in Blaauw, M. (ed.) Contrastivism in Philosophy: New Perspectives. London: Routledge.

Schroeder, M. 2007. Slaves of the Passions. Oxford: Oxford University Press.

__ 2008. "Having Reasons." Philosophical Studies 139: 57-71.

- 2011. "What Does It Take to 'Have' a Reason?" in Reisner, A. and Steglich-

Petersen, A. (eds.) Reasons for Belief. Cambridge: Cambridge University Press.

- 2012. "Stakes, Withholding, and Pragmatic Encroachment on Knowledge." Philosophical Studies 160.2: 265-285.

- 2015. "Knowledge Is Belief for Sufficient (Subjective and Objective) Reason." Oxford Studies in Epistemology 5: 226-252.

Shaheen, J. Forthcoming. "Ambiguity and Explanation". Inquiry.

Sinnott-Armstrong, W. 2008. "A Contrastivist Manifesto." Social Epistemology 22.3: 257-70.

Snedegar, J. 2013a. "Negative Reason Existentials." Thought 2: 108-116.

___ 2013b. "Reason Claims and Contrastivism about Reasons." Philosophical Studies 166: 231-242.

__ 2015. "Contrastivism about Reasons and Oughts." Philosophy Compass 10.6: 379-388.

Sperber, D. \& Wilson, D. 1986. Relevance: Communication and Cognition. Oxford: Blackwell.

Stanley, J. 2005. Knowledge and Practical Interests. Oxford: Oxford University Press.

Stine, G. 1976. "Skepticism, Relevant Alternatives, and Deductive Closure." Philosophical Studies 29: 249-261.

Strevens, M. 2007. "Mackie Remixed" in Campbell, J., O’Rourke, M. and Silverstein, H. (eds.) Causation and Explanation. Cambridge MA: The MIT Press.

Swanson, E. 2010. "Lessons from the Context-Sensitivity of Causal Talk." Journal of Philosophy 107.5: 221-242.

__ 2012. "The Language of Causation" in The Routledge Companion to the Philosophy of Language. Routledge.

van Frassen, B. 1980. The Scientific Image. Oxford: Oxford University Press. 